\title{
Just Enough: An introduction
}

\author{
Matthew Ingleby and Samuel Randalls
}

In Donna Summer's and Barbra Streisand's 1979 hit duet, 'No more tears', the refrain 'Enough is Enough' articulates the cry of the wounded party in a damaging relationship on the verge of a break up. Severance is inevitable: the strains have been too great. The phrase's tautological simplicity seeks to place its message beyond challenge. That which has been endured for so long has reached 'tipping point' and one is impelled to act not by choice but necessity, calling time only on the intolerable.

It is a phrase that has become increasingly popular as a slogan within our angry, atomised political culture, being recruited for various single-issue campaigns, pursuing all manner of ends. A promiscuously used part of the popular lexicon, 'enough is enough' has recently been deployed in relation to, among other causes, Facebook's ability to control what is done with its users' data; ${ }^{1}$ the continued claims of anti-semitism within the British Labour party; ${ }^{2}$ the need to 'stand up' to Russia following the alleged poisoning in Salisbury, UK $;^{3}$ and Donald Trump's determination to engage in a trade war with China. ${ }^{4}$ The phrase has recently had particular traction in debates concerning gun control and, relatedly, police brutality towards ethnic minorities in the US. When the Democrats sat down on the floor of Congress to protest over the lack of gun control legislation, 'Enough is enough' was their slogan, as it was again when students protested to state lawmakers and Donald Trump about the February 2018 school shooting in Florida. ${ }^{5}$ When Jennifer Wolfe wrote on the Huffington Post to decry systemically racist police violence, she echoed others in the Black Lives Matter movement in saying 'enough is enough' 6

In an age of Sanders, Corbyn, Syriza, Trump, Brexit, not to mention the more extreme and violent decimation of the self-proclaimed centre ground in other parts of the world such as the Middle East, we appear to be living in an age whose increasingly default posture has become precisely 'enough is enough'. But how does the phrase function materially in the current political climate? In relation to gun control and racialized police brutality in the States, it would appear that the bland tautological strength of the statement is posed in direct proportion to the sheer intractability of its opposition. One suspects, after all, that there is no 'sufficiency' of black lives that can be lost for the conservative gun lobby for them to renounce the dubious freedom to own dangerous weapons and carry them in public. How many times would one have to say 'enough is enough' for the message to get through to those to whom it is directed? How much vocalized anger would be sufficient?

\footnotetext{
${ }^{1}$ https://www.independent.co.uk/news/business/news/facebook-cambridge-analytica-data-scandal-advertisersenough-isba-mc-saatchi-a8268326.html

${ }^{2}$ https://www.thetimes.co.uk/article/enough-is-enough-prstrf3fd

${ }^{3} \mathrm{https}$ ///news.sky.com/story/enough-is-enough-boris-johnson-says-world-is-at-turning-point-over-russia11307586

${ }^{4}$ https://www.newsmax.com/politics/white-house-china-donald-trump-tariffs/2018/04/06/id/853090/

${ }^{5} \mathrm{https}$ ://www.theguardian.com/us-news/2018/feb/21/florida-students-confront-lawmakers-on-gun-control-asthousands-walk-out

${ }^{6}$ http://www.huffingtonpost.com/jennifer-wolfe/enough-is-enough-arent-yo b 10930248.html Dwayne Wade: 'The endless gun violence in places like Chicago, Dallas, not to mention Orlando - it has to stop. Enough! Enough is enough.' http://www.dailymail.co.uk/news/article-3689490/LeBron-James-fellow-basketball-playersBlack-Lives-Matter-speech-ESPYs-calling-end-shoot-kill-mentality.html
} 
The quantity, volume and shrillness with which the slogan is screamed suggests, perhaps, on some level, that we know it does not mean what it says. The potency of any moral appeal is grounded in its receptibility, after all, and receptibility depends upon positionality, ideology, culture. In a world of multiple and clashing positionalities, ideologies, and cultures, the rhetorical weapon that 'enough is enough' could embody is blunted, because what 'enough' constitutes itself remains in contest. Maybe, then, we say 'enough is enough' not really to signal that a tipping point has been reached but as a verbal substitute for change - when we have come to the 'end of our tether' but there is still no sign of amelioration at hand. 'Enough is enough' might then be a compensation for a lack, perceived or real, of material power. As such, the mantra might be said to work not so much as a rallying call but a prophylactic, its repetition drowning out the complex dialogue that is required for global society to move towards a position where the structural transformations to the political and economic sphere necessary for it to be able to correct some of the seemingly intractable situations it currently faces might be possible.

Of all the intractable situations the 'enough is enough' mantra is standardly invoked to mount a challenge to - or distract from - the twinned issues of global inequality and climate change are the most pressing and complex. In the discourses that surround these issues, the mantra of 'enough is enough', moreover, is loaded with substantially more weight than it bears in some of the other contexts in which it is used, given that the causes of social justice and sustainability are specially invested in concepts of 'enough' and 'sufficiency'. One way, indeed, of putting in simple terms the challenge raised within policy circles that mediate these two causes might be thus: 'how do we ensure citizens globally all have a good enough standard of living in the present whilst also ensuring that we have done enough to secure the sustainability of the planetary environment?' From the perspective of affluence in the Global North, it is clear that we are currently not doing 'enough' from either a justice or an environmental perspective, let alone both. As Anders Hayden argued in When Green Growth is not Enough (2014), the policy frameworks currently in play by governments worldwide are insufficiently radical to prevent ecological catastrophe from occurring, thereby exacerbating further political tensions caused by pre-existing economic inequality. No matter how much we say 'enough is enough' with regard to the twin project for an environmentally and socially 'just enough', the actual construction of the kind of 'sufficiency economy' requisite to achieve such a project looks excessively utopian and unreachable at present.

Bearing in mind the peculiar topical energies and tensions at work in the role of "enough rhetoric' in current debates about global social justice and sustainability, this book attempts to shed new light on 'sufficiency', by exploring the idea in a range of contexts, historical and disciplinary. In exploring 'enough', this book addresses a concept that plays a major but undertheorised role in presentist policy discourse but whose historical trajectory and culturallinguistic contours have as yet failed to be properly appreciated.

$* * * * * * * * * * * * * * * *$

While 'enough' is often brandished in a manner that claims to be transparently obvious, it is never neutral or universal, and often bears complex political inflections. When we start to think about the way it is deployed, in specific cultural situations and in particular historical moments, certain tensions, contradictions and even opacities within 'sufficiency' and 'enough' emerge. Consider the problem of 'enough food', so important to the project of securing a just and sustainable planet, implicated as it is in questions about population, industrial agriculture and the growing pressures on the use of land in 'the Anthropocene'. Do we mean enough food to 
survive, enough to feel full, enough to maintain an active lifestyle, enough meat to show respect for guests at banquets, or, even, enough to cultivate specific identities, for example, the proteinhungry muscular toned body types fashionable among bodybuilders? Enough food appears to be a qualitative judgement as much as a quantitative indicator, bounded by cultural norms as well as a plethora of concerns about whether diets are 'balanced' and whether food is 'healthy'. Contestations over the genetic modification of food or the idea of food pills suggest that merely having 'enough' food is not the same as having enough of the right kind of food. Indeed, such claims have been used by free-marketeers to argue that (rich people's) environmental concerns limit the use of technology to deliver sufficient food to the starving (Driessen, 2003). Having one's 'daily bread', as Ethan Shagan reminds us, does not imply a singular vision of 'enough'. Bread may be one of the most universal foodstuffs, yet the idea of what a satisfactory portion might constitute varies across cultures and has undergone significant transitions in different historical periods. However insistent the slogan, 'enough' simply isn't an unchanging, universal horizon, to judge whatever is the amount in hand by. One idea or use of sufficiency is not equal to another, as they rely on codes, assumptions, and ideologies, which need to be analysed and made visible.

This book offers a distinctive way of thinking through the problems that 'enough' raises, offering a few different case studies of the complexities at work in the term in various particular times or scenarios, which are presented to stimulate critical thought about 'sufficiency' more broadly. Rather than trying to fix the concept or rein in its ideological or political multiplicity, we wish to demonstrate the slippages always already present in deployments of enough. As Kathryn Allan notes in her chapter, enough is "highly polysemous", being used both as a term with qualification (just enough) and a term that indicates a degree of over-emphasis ("enough already', or the Italian, 'Basta!'). While accounts of 'having enough' (but not too little or too much) are used politically to craft policy discourse from alcohol consumption to austerity economics, increasing numbers of citizens have also 'had enough' of such governmental invocations and stand ready to contest what 'enough' means. The idea of enough might be crafted to draw a line or classification beyond which would be too much, but that line can never be other than political because it never self-evidently manifests itself (whether through science or any other technical means). 'Enough' might present itself as a yardstick to measure the value of policies against but is actually relative and culturally mediated.

This basic relativity in the term has already been noted by sustainability proponents (e.g. Skidelsky and Skidelsky, 2013) who show how the slippage of 'enough' within capitalist discourse has been productive for capitalism. 'Enough' never achieves fixity in capitalism, being always defined in relation to all the other moving parts of our cultural and ideological infrastructure, including the new material desires produced through advertising to power everevolving consumer demand. The concept of what is 'enough' to live 'the good life' has grown consistently for the last 50 years, rising in a way that has created a credit-led consumption economic model that fuels further consumption. We only feel we 'have enough' when we have at least as many goods and wealth as the people around us; and without any bounds on consumption, this drives an ever-increasing claim for what should be the basic minimum acceptable conditions to live well. The Skidelskys' political rallying cry is to turn 'enough' into a radical restatement of a different life, one that has had enough of capitalist duplicity and instead seeks a form of sufficiency lifestyle. These types of claims have spawned a burgeoning literature that argues for the need for a new society based on concepts of enough or sufficiency (e.g. Alexander, 2015; Dietz and O'Neill, 2003; Hayden, 2014). Concerned with possible limits to economic growth, material resource availability, efficiency of use and a fear that contemporary imperatives for consumerism have drawn attention away from time, wellbeing 
and equity, these books espouse an approach founded on contentment rather than desire - a 'small is beautiful' rationale (Schumacher, 1973).

But 'sufficiency lifestyles' and the limits they attempt voluntarily to erect have long been coopted within capitalism for its own limitless ends, as a number of scholars have shown. Elizabeth Shove's (2003) work on domestic technologies, for instance, highlights how new technologies do not just enhance energy efficiency or save time, but re-shape everyday practices in ways that can lead to the further consumption of other energy-using practices (Shove, 2003). In our economy, not having enough time powers the demand for and innovation of more and more 'convenience' products, even though the time we save through such products is rarely put to anything other than more labour of one kind or another. Ready meals and microwaves and washer-dryers for clothes represent examples of time-saving inventions which have opened up new opportunities for work or leisure (particularly for women), but which mean we no longer 'have time' to prepare meals from fresh food or wash and dry clothes without consuming vast amounts of energy. Enough time is a malleable notion, as the demands to 'save time' re-shape practices in ways that mean we demand ever more convenience, yet perennially feel like we still do not have enough time. The question of whether we have 'enough' of time, money, pension, clothes, indeed, appears to be increasingly muddied, as capitalism makes increasingly ingenious use of and preys upon our anxieties about scarcity. As Rebecca Collins shows in her chapter, twenty-first century social media systems collaborate with throw-away fashion culture to make us feel like we are not consuming enough: our sense of what might constitute having enough clothes has become mediated by the concern that friends on Facebook might 'catch' us in the same outfit twice. The fear of not having enough is so embedded in and woven into the everyday practices of capitalist modernity that it will be difficult to shake off.

To try to change this attitude, it is tempting to engage in quantitative statements of what is 'enough', but not too much. 'Enough' is often therefore presented in absolute quantitative terms, enumerated in a way that invokes precise baselines for what might be too little or too much in a given context. But the concept itself is resistant to quantification and always comes with a political and legal burden of qualification and questions about enactment. Even if 'enough' could be defined, it would not necessarily offer us a guide to action. As Thomas Princen (2005) has demonstrated, enough is contextually specific and it is a 'philosophy' of enough that guides actions more than any quantitative measure, an attitude by individuals or communities that know "how to ask how much is too much" (Princen, 2005: 289). Likewise, Sam Berry (2007a; 2007b) draws inspiration from Biblical examples to suggest that a good like should be about living with careful stewardship and contentment with a moderate life. Living "authentic Christian lives" (Stafford and Bryant, 2007: 168) involves the three Rs of restraint, re-use and recycle. Enough becomes a moral value. Morality is centre stage in discussions of the right distribution of resources in a society and whether the rich and poor have equivalent enoughness (Shagan) and in the temperance movement's arguments for moderate drinking (Kneale). 'Enough' adapts to fit and flesh out moral arguments.

The value-laden, political nature of enough is a central task that this book sets out to explore and which we hope will be taken up through further scholarship. The polysemous nature of enough (Allan) needs to be grappled with and politicised. Looking forward to future claims for sustainable worlds, of living with enough but no more, also requires us to look back or else we misunderstand the flexibility built into the term and propose enough as a solution to fix all the world's ills. 


\section{Chapter summaries}

Assembling this eclectic collection of essays, each of which concretizes a specific context in which the problem of 'enough' is explored, is intended to set at a slant and de-familiarise a term that has achieved a certain blandness verging on invisibility through its over-use in a number of key policy arena, prime of which are planetary sustainability and global equality. Its very eclecticism of discipline and focus is designed to make a point, resisting the utopian, technocratic simplicity of much policy discourse by emphasising the complex messiness in practice of one concept on whose self-evidential simplicity so much else had depended.

We open the book with Allan's chapter exploring the linguistic connotations and uses of the term enough. Exploring diverse deployments of the term enough from dictionary definitions to newspaper stories, Allan argues that the complexity and diverse meanings of the term enough underpin rather important conceptual difficulties in parallel terms like sufficiency. Indeed Allan's argument is beautifully illustrated by the following chapters which all highlight how in different historical contexts what it means to have enough, in contrast to too much or not enough, is debated and variegated.

Skoda's chapter presents a historical narrative of how enoughness changed in the $13^{\text {th }}$ and $14^{\text {th }}$ centuries as sufficiency was used to reason through and debate changes in social values and increasing commercialisation. A focus on moderation and things being in their proper place, helped institutionalise an ideal of enough as a concept which would apply distinctively to people from different classes. What was enough, but not too much, depended on whether one was of high social standing or not. Not least, this reflected growing concerns about a shortage of labour if the social hierarchy wasn't maintained. Indeed, as Skoda argues, this sense that enough should be contextualised by class has remained an enduring legacy of the later Middle Ages articulation of enough.

In Early Modern England, likewise, there was a lively debate about where 'virtuous sufficiency' became 'sinful excess', as Shagan puts it in his chapter. Shagan explores Bernard Mandeville's intervention into this debate highlighting how his proto-capitalist ethics informed an understanding of sufficiency as being dictated more by the market than by a moral code of one's daily bread (as in the Lord's prayer). In other words, for the wealthy there was no such thing as excess. As Shagan points out, this trust in unlimited consumption has been foundational to the development of the environmental problems we see today.

In the Victorian era, Edward Carpenter pondered the consumerism and waste that this unlimited view of excess had produced. As Parkins chapter goes on to show, Carpenter inspired followers who donned home-made clothes and ate home-grown vegetables as they pursued a sustainable life. But as Parkins points out, we need to be careful with this reading of Carpenter, because he was equally convinced that sufficiency in everyday life would expand the realm of sensory pleasure. Rather than enough being a moral restraint or constraint, living simply opened up new opportunities and enjoyment, an attitude that is strikingly at odds with much of the language environmentalist invocations are couched within.

In the rather different context of alcohol consumption, the question of what counted as 'enough' was vigorously debated throughout the Victorian period by teetotallers, moderationists and others. In his chapter, Kneale argues that attempts at quantifying a sufficient amount of alcohol were nested within contrasting views of alcohol in the $19^{\text {th }}$ and $20^{\text {th }}$ century, where alcohol as food or medicine might constitute a daily requirement, while concerns for 'problem drinking' 
focused on daily maximums. What was enough in terms of alcohol also crucially came to depend on whether it was the drink that was considered to be the problem, or the drinker. Reviewing over a century's worth of contestation, Kneale concludes that defining 'enough' (not too much) has been the central question for an alcohol policy led largely by an ideal of moderation.

When it comes to other $20^{\text {th }}$ and $21^{\text {st }}$ century articulations of enough, these are often more closely aligned with contemporary environmental and social values. Collins chapter highlights how young people have contrasting experiences and expectations of sufficiency when it comes to everyday practices. While invoking attitudes of care for the environment and others, young consumers are also torn between other expectations. Enough might be about having enough clothes so that pictures on social media do not reflect the same dress every time. Any quantified environmental or consumer standards of what might be sufficient are therefore translated through a social standard of consumption identity.

Alexander's chapter is a programmatic statement of the $21^{\text {st }}$ century form of enough, setting out the contours of what a society based on sufficiency might look like. It is future-oriented, indeed in some interesting ways parallels some previous future imaginaries e.g. of Edward Carpenter (see Parkins chapter). Alexander sets out a radical vision for a future sufficiencybased economy that would sustainably manage water, food, and energy resources. Alexander sets out what we might think of as a very contemporary articulation of enough, looking at declining environmental resources and the necessity for a sustainable use society. This is in many ways what we expect some of our readers to think of in terms of enoughness, but we hope that reading this in context of the rest of the volume, highlights that what is considered to be enough really does vary between different times and places.

\section{References}

Alexander, S. 2015. Sufficiency Economy: Enough, For Everyone, Forever, Simplicity Institute Publishing.

Berry, R.J. 2007a. (ed) When Enough is Enough: A Christian framework for environmental sustainability, Nottingham: Inter-Varsity Press.

Berry, R.J. 2007b. Sustainability: God's way or greenwash?, In: Berry, R.J. (ed) When Enough is Enough: A Christian framework for environmental sustainability, Nottingham: Inter-Varsity Press, 11-34.

Carter, S. 2007. Rise and Shine: Sunlight, technology and health, Oxford: Berg.

Daly, H. 2008. A steady-state economy, London: Sustainable Development Commission. (http://www.sd-commission.org.uk/data/files/publications/Herman_Daly_thinkpiece.pdf).

Dietz, R. and O'Neill, D. 2013. Enough is Enough: Building a sustainable economy in a world of finite resources, London: Routledge.

Driessen, P. 2003. Eco-Imperialism: Green Power Black Death, Bellevue, WA: Free Enterprise Press. 
Dry, S. 2007. Fishermen and forecasts: How barometers helped make the Meteorological Department safer in Victorian Britain. Centre for Analysis of Risk and Regulation Discussion Paper 46, London: London School of Economics.

Foster, J.B. and Magdoff, H. 2010. What every environmentalist needs to know about capitalism. Monthly Review, 61(10): 1-30.

Hayden, A. 2014. When green growth is not enough: Climate change, ecological modernization and sufficiency, Montreal, QC: McGill-Queen's University Press.

Jankovic, V. 2006. The last resort: A British perspective on the medical South, 1815-1870, Journal of Intercultural Studies, 27(3): 271-298.

Princen, T. 2005. The logic of sufficiency, Cambridge, MA: MIT Press.

Sachs, W. 1999. Planet Dialectics: Explorations in Environment and Development, London: Zed Books.

Sayre, N. 2008. The genesis, history and limits of carrying capacity, Annals of the Association of American Geographers, 98, 1, 120-134.

Schumacher, E.F. 1973. Small is beautiful: A study of economics as if people mattered, London: Blond and Briggs.

Shove, E. 2003. Comfort, cleanliness and convenience, Oxford: Berg.

Skidelsky, E. and Skidelsky, R. 2013. How much is enough? Money and the good life, New York, NY: Penguin.

Stafford, D. and Bryant, J. 2008. Sustainability, resources and waste, In: Berry, R.J. (ed) When Enough is Enough: A Christian framework for environmental sustainability, Nottingham: Inter-Varsity Press, 155-168. 